\title{
Characterization of phenolic compounds in wild medicinal flowers from Portugal by HPLC-DAD-ESI/MS and evaluation of antifungal properties
}

\author{
Lillian Barros $^{\mathrm{a}, \mathrm{b}}$, Carlos Tiago Alves $^{\mathrm{c}}$, Montserrat Dueñas ${ }^{\mathrm{b}}$, Sónia Silva ${ }^{\mathrm{c}}$, Rosário Oliveira ${ }^{\mathrm{c}}$, \\ Ana Maria Carvalho ${ }^{a}$, Mariana Henriques ${ }^{c, * *}$, Celestino Santos-Buelga ${ }^{b}$, Isabel C.F.R. Ferreira ${ }^{a, *}$ \\ a CIMO/Escola Superior Agrária, Instituto Politécnico de Bragança, Campus de Santa Apolónia, Apartado 1172, 5301 -855 Bragança, Portugal \\ b Grupo de Investigación en Polifenoles (GIP-USAL), Facultad de Farmacia, Universidad de Salamanca, Campus Miguel de Unamuno, 37007 Salamanca, Spain \\ ${ }^{\mathrm{c}}$ IBB - Institute for Biotechnology and Bioengineering, Centre of Biological Engineering, University of Minho, 4710-057 Braga, Portugal
}

\section{A R T I C L E I N F O}

\section{Article history:}

Received 26 June 2012

Received in revised form 11 October 2012

Accepted 2 November 2012

\section{Keywords}

Medicinal flowers

Phenolic compounds

HPLC-DAD-ESI/MS

Candida species

Antifungal effect

\begin{abstract}
A B S T R A C T
In the present work, the phenolic compounds of Castanea sativa, Filipendula ulmaria and Rosa micrantha flowers from Northeastern Portugal were characterized by HPLC-DAD-ESI/MS. Furthermore, it was performed a screening of their antifungal potential against Candida species (Candida albicans, Candida glabrata, Candida parapsilosis and Candida tropicalis).

C. sativa sample gave the highest amount of phenolic compounds $(18973 \pm 40 \mu \mathrm{g} / \mathrm{g}$, fw) and hydrolysable tannins $(14873 \pm 110 \mu \mathrm{g} / \mathrm{g})$. The highest amounts of phenolic acids $(569 \pm 20 \mu \mathrm{g} / \mathrm{g}) \mathrm{and}$ flavonoids $(6090 \pm 253 \mu \mathrm{g} / \mathrm{g})$ were obtained in F. ulmaria and $R$. micrantha samples, respectively. Hydrolysable tannins (e.g. tri and digalloyl HHDP glucose) were the main group of phenolic compounds in C. sativa and F. ulmaria samples, while flavonoids (e.g. (+)-catechin and procyanidin dimers and trimers) were the most abundant group in $R$. micrantha. Thus, the stronger effect showed by this latter against all the Candida species (MIC $\leq 0.155 \mathrm{mg} / \mathrm{mL}$ ) and, particularly its fungicide effects in C. glabrata, might be related to the mentioned flavonoids that were inexistence in the other samples.
\end{abstract}

(C) 2012 Elsevier B.V. All rights reserved.

\section{Introduction}

In healthy individuals, many species of Candida are endogenous commensals of the gastrointestinal and urogenital tracts (Soll, 2002). However, the prevalence of opportunistic fungal infections has been increasing dramatically over the recent decades and this is particularly evident in immunocompromised individuals, where these species become frequently opportunistic pathogens (Pfaller and Diekema, 2007). Although, Candida albicans has been regarded as the most common causative agent of fungal infection in humans, nowadays other non-C. albicans Candida (NCAC) species such as Candida glabrata, Candida tropicalis, and Candida parapsilosis, are emerging as significant nosocomial pathogens (Silva et al., 2010). Moreover, NCAC species tend to be inherently less susceptible to the available antifungal drugs like the azole drugs and their derivatives, which continue to dominate as the antifungal agents of choice against Candida-related infections (Redding et al., 2002; Hajjeh et al., 2004; Ruhnke, 2006). Furthermore this difficulty highlights

\footnotetext{
* Corresponding author. Tel.: +351 273303219; fax: +351 273325405

** Corresponding author. Tel.: +351 253604408; fax: +351 253604429

E-mail addresses: mcrh@deb.uminho.pt (M. Henriques), iferreira@ipb.pt (I.C.F.R. Ferreira).
}

the necessity to develop new alternative antifungal agents, in order to increase the spectrum of activity against Candida species.

In the recent years the interest in natural compounds has raised, specifically some phenolic compounds including phenolic acids and flavonoids have been reported to inhibit various pathogenic bacteria and fungi (Rauha et al., 2000; Erasto et al., 2004; Tepe et al., 2004). Previous work conducted by our research group has highlighted the importance of wild plants as sources of phenolic compounds, such as phenolic acids, flavonoids and anthocyanins (Barros et al., 2011a). Moreover, flowers from semiwild and wild species such as Castanea sativa, Filipendula ulmaria and Rosa micrantha have been traditionally used for several folk medicinal applications. Decoctions of $C$. sativa flowers are used for colds, cough, diarrhea and cholesterol; infusions of $F$. ulmaria are used for pneumonia and flu, urinary tract infections, rheumatism and headache; and rosewater and decoctions of $R$. micrantha are used for acne, skin condition and injuries and eye inflammations (Camejo-Rodrigues et al., 2003; Novais et al., 2004; Neves et al., 2009; Carvalho, 2010). Their antioxidant potential was already reported by us (Barros et al., 2010, 2011b; Guimarães et al., 2010).

As far as we know there are no reports neither on antiNCAC activity of the mentioned wild flowers, nor in phenolic composition of $R$. micrantha. The available studies in literature described phenolic composition in $C$. sativa leaves (Calliste et al., 2001) and heartwood (Sanz et al., 2010), but not in its flowers. 
The phenolic composition of F. ulmaria flowers was studied, but with plant material from other European countries, i.e. not growing under Mediterranean particular climatic and soil conditions (Krasnov et al., 2006, 2009; Shilova et al., 2006; Pemp et al., 2007; Fecka, 2009; Harbourne et al., 2009). These flowers revealed the presence of a number of polyphenolic constituents including salicylates (e.g. spiraein, salicylic acid and methyl salicylate), flavonols (e.g. spiraeoside, hyperoside, rutin, kaempferol $4^{\prime}$-O-glucosides, quercetin-4'-O- $\beta$-D-galactopyranoside and quercetin-3-O- $\beta$ glucopyranoside) and ellagitannins (tellimagrandins I and II, and rugosin D) (Krasnov et al., 2006, 2009; Shilova et al., 2006; Pemp et al., 2007; Fecka, 2009; Harbourne et al., 2009).

It has been indicated that the antifungal activity of plant extracts is related to the different compounds present (with diverse functional groups and chemical substituents) and to possible synergistic interactions between them (Dorman and Deans, 2000). Therefore, in the present work, an exhaustive characterization of the phenolic compounds present in the extracts of $C$. sativa, F. ulmaria and $R$. micrantha flowers was carried out by HPLC-DAD-ESI/MS. Furthermore, a screening of the antifungal potential of those extracts against Candida species was also performed.

\section{Materials and methods}

\subsection{Samples}

Several ethnobotanical surveys conducted in Portugal for the last 10 years (Camejo-Rodrigues et al., 2003; Novais et al., 2004; Neves et al., 2009; Carvalho, 2010) highlighted the importance of folk medicine founded on traditional uses of plants. Considering our group previous research (Barros et al., 2010, 2011a, 2011b), several species were chosen to be screened for antifungal activity and further characterization, but only three of them highlight as interesting species: C. sativa Mill, F. ulmaria (L.) Max and R. micrantha Borrer ex Sm.

Flowers and inflorescences (the parts most cited for folk medicinal purposes by key-informants) of the selected species were collected in the Natural Park of Montesinho territory (Trásos-Montes, Northeastern Portugal), in 2009, according to local medicinal criteria of use and each plant growth pattern. C. sativa, the upright catkins during anthesis (flower fully opened and functional) in late summer; F. ulmaria, the inflorescences with flowers fully open and functional in early summer; R. micrantha, the petals removed from floral buds and also from flowers after anthesis (anthers already opened, stamens becoming dry) in early spring.

Voucher specimens are kept at the Herbário da Escola Superior Agrária de Bragança (BRESA). Each sample was lyophilized (Ly-8FM-ULE, Snijders, Netherlands) and stored in the deep-freezer at $-20^{\circ} \mathrm{C}$ for subsequent analysis.

\subsection{Standards and reagents}

HPLC-grade acetonitrile was obtained from Merck KgaA (Darmstadt, Germany). Formic and acetic acids were purchased from Prolabo (VWR International, France). The phenolic compounds standards were from Extrasynthese (Genay, France). RPMI 1640 medium was purchased from Sigma (St. Louis, MO, USA). All other chemicals were of analytical grade and purchased from chemical suppliers. Water was treated in a Milli-Q water purification system (TGI Pure Water Systems, USA).

\subsection{Preparation of the extracts}

Each sample ( $1 \mathrm{~g}$ ) was extracted with $30 \mathrm{~mL}$ of methanol:water $80: 20(\mathrm{v} / \mathrm{v})$ at room temperature, $150 \mathrm{rpm}$, for $1 \mathrm{~h}$. The extract was filtered through Whatman no. 4 paper. The residue was then reextracted twice with additional $30 \mathrm{~mL}$ portions of methanol:water $80: 20(\mathrm{v} / \mathrm{v})$. The combined extracts were evaporated at $35^{\circ} \mathrm{C}$ (rotary evaporator Büchi R-210) to remove methanol. The aqueous phase was lyophilized and re-dissolved in (a) $20 \%$ aqueous methanol at $5 \mathrm{mg} / \mathrm{mL}$ and filtered through a $0.22-\mu \mathrm{m}$ disposable LC filter disk for high performance liquid chromatography (HPLC) analysis or (b) distilled water at $200 \mathrm{mg} / \mathrm{mL}$ for antifungal assays.

\subsection{Phenolic compounds identification and quantification}

The extracts were analyzed using a Hewlett-Packard 1100 chromatograph (Agilent Technologies) with a quaternary pump and a diode array detector (DAD) coupled to an HP Chem Station (rev. A.05.04) data-processing station. A Waters Spherisorb S3 ODS-2 $\mathrm{C}_{18}, 3 \mu \mathrm{m}(4.6 \mathrm{~mm} \times 150 \mathrm{~mm})$ column thermostatted at $35^{\circ} \mathrm{C}$ was used. The solvents used were: (A) $0.1 \%$ formic acid in water and (B) acetonitrile. The elution gradient established was $10 \%$ B to $15 \%$ B over $5 \mathrm{~min}, 15-25 \%$ B over $5 \mathrm{~min}, 25-35 \%$ B over $10 \mathrm{~min}$, isocratic $50 \% \mathrm{~B}$ for $10 \mathrm{~min}$, and re-equilibration of the column, using a flow rate of $0.5 \mathrm{~mL} / \mathrm{min}$. Double online detection was carried out in the DAD using $280 \mathrm{~nm}$ and $370 \mathrm{~nm}$ as preferred wavelengths and in a mass spectrometer (MS) connected to HPLC system via the DAD cell outlet.

MS detection was performed in a API 3200 Qtrap (Applied Biosystems, Darmstadt, Germany) equipped with an ESI source and a triple quadrupole-ion trap mass analyzer that was controlled by the Analyst 5.1 software. Zero grade air served as the nebulizer gas (30 psi) and turbo gas for solvent drying $\left(400^{\circ} \mathrm{C}, 40 \mathrm{psi}\right)$. Nitrogen served as the curtain ( $20 \mathrm{psi}$ ) and collision gas (medium). The quadrupols were set at unit resolution. The ion spray voltage was set at $-4500 \mathrm{~V}$ in the negative mode. The MS detector was programmed to perform a series of two consecutive modes: enhanced MS (EMS) and enhanced product ion (EPI) analysis. EMS was employed to record full scan spectra so as to obtain an overview of all of the ions in sample. Settings used were: declustering potential (DP) $-450 \mathrm{~V}$, entrance potential $(\mathrm{EP})-6 \mathrm{~V}$, collision energy (CE) $-10 \mathrm{~V}$. Spectra were recorded in negative ion mode between $\mathrm{m} / \mathrm{z}$ 100 and 1000. Analysis in EPI mode was further performed in order to obtain the fragmentation pattern of the parent ion(s) detected in the previous experiment using the following parameters: DP $-50 \mathrm{~V}$, $\mathrm{EP}-6 \mathrm{~V}, \mathrm{CE}-25 \mathrm{~V}$, and collision energy spread (CES) $0 \mathrm{~V}$.

The phenolic compounds present in the samples were characterized according to their UV and mass spectra and retention times compared with commercial standards when available. For the quantitative analysis of phenolic compounds, a calibration curve was obtained by injection of known concentrations $(2.5-100 \mu \mathrm{g} / \mathrm{mL})$ of different standards compounds: catechin $(y=132.76 x-59.658$; $\left.R^{2}=0.9997\right) ; \quad$ caffeic acid $\left(y=617.91 x-691.51 ; \quad R^{2}=0.9991\right)$; gallic acid $\left(y=556.94 x-738.37 ; \quad R^{2}=0.9988\right) ; \quad$ isorhamnetin $\left(y=629.14 x-2323.4 ; \quad R^{2}=0.9967\right) ;$ isorhamnetin-3-O-glucoside $\left(y=262.31 x-9.8958 ; \quad R^{2}=1.000\right) ; \quad$ kaempferol-3-O-glucoside $\left(y=190.75 x-36.158 ; \quad R^{2}=1.000\right) ; \quad$ kaempferol-3-O-rutinoside $\left(y=175.02 x-43.877 ; R^{2}=0.9999\right) ;$ myricetin $(y=778 x-1454.3$; $\left.R^{2}=0.9990\right)$; $\quad$ quercetin-3-O-glucoside $\quad(y=316.48 x-2.9142$; $\left.R^{2}=1.000\right) ;$ and quercetin-3-O-rutinoside $(y=222.79 x-243.11$; $R^{2}=0.9998$ ); The results were expressed in $\mu \mathrm{g} / \mathrm{g}$ of fresh weight (fw), as mean \pm standard deviation of three independent analyses.

\subsection{Antifungal activity}

Four reference strains from the American Type Culture Collection (ATCC) namely C. albicans (ATCC 90028), C. tropicalis (ATCC 750), C. glabrata (ATCC 2001) and C. parapsilosis (ATCC 22019) were used in the course of this study. Before the experiments, all strains 
were grown on Sabouraud Dextrose Agar (SDA; Merck, Germany) for $24 \mathrm{~h}$ at $37^{\circ} \mathrm{C}$. Yeast cells from at least five colonies ( $1 \mathrm{~mm}$ diameter) were suspended in $5 \mathrm{~mL}$ of sterile saline solution $(0.85 \% \mathrm{NaCl})$. The resulting yeast suspension was mixed for $15 \mathrm{~s}$ with a vortex. Then, the suspension was adjusted by spectrophotometric method, adding saline solution to reach the value of the $0.5 \mathrm{McF}$ arland scale. The process makes final inocula of $3.0 \pm 2.0 \times 10^{6}$ cells $/ \mathrm{mL}$.

Minimal inhibitory concentration (MIC) was determined according with the guidelines from the CLSI M27-A2 document (NCCLS, 2002) with some modifications. Thus, serial dilutions of the three plant extracts $(0.05,0.155,0.625,1.25,2.5$ and $5 \mathrm{mg} / \mathrm{mL})$ were prepared in RPMI 1640 medium at $\mathrm{pH}$ 7. Aliquots of each plant extract $(100 \mu \mathrm{L})$, at a twofold final concentration, were dispensed into the 96-well plates (Orange Scientific, Braine-l' Alleud, Belgium). Furthermore, the plates were also incubated with aliquots $(100 \mu \mathrm{L})$ at a twofold concentration of the four Candida species. Drug-free and yeast controls were also included.

The 96 -well plates were incubated at $37^{\circ} \mathrm{C}$ for $48 \mathrm{~h}$. After visualization of the resultant plate the MIC value was correspondent to the antifungal concentration where there was no growth, by comparison with the control (cells grown without extract). Moreover, the number of viable cells was assessed by the determination of number of colony forming units (CFUs). CFUs were enumerated by plating $10 \mu \mathrm{L}$ of each cell suspension (from each well) onto SDA. After $24 \mathrm{~h}$ of incubation at $37^{\circ} \mathrm{C}$, the number of colonies formed was counted. These experiments were performed three times and, at least, in quadruplicate.

\section{Results and discussion}

\subsection{Identification and quantification of phenolic compounds present in the extracts from wild flowers}

The extraction yields for $R$. micrantha and $C$. sativa samples were similar $(33.16 \% \pm 1.22 \%$ and $35.80 \% \pm 1.87 \%$, respectively), being slightly higher than the one obtained for $F$. ulmaria $(27.56 \% \pm 2.01 \%)$. Fig. 1 shows the phenolic compounds profile of $C$. sativa, F. ulmaria and $R$. micrantha flowers extracts. The obtained profiles included phenolic acids, flavonoids including procyanidins, and hydrolysable tannins. Data (retention time, $\lambda_{\max }$ in the visible region, molecular ion and main fragment ions observed in $\mathrm{MS}^{2}$ ) obtained by HPLC-DAD-ESI/MS analysis, identification of compounds and individual quantification are presented in Table 1.

Total amounts of the different phenolics groups in the three plant samples are shown in Fig. 2. Hydrolysable tannins were the main group in $C$. sativa and $F$. ulmaria samples, while flavonoids including procyanidins were the most abundant group in $R$. micrantha. C. sativa sample gave the highest amount of phenolic compounds $(18973 \pm 40 \mu \mathrm{g} / \mathrm{g}$, fw) and hydrolysable tannins $(14873 \pm 110 \mu \mathrm{g} / \mathrm{g})$. The highest amount of phenolic acids $(569 \pm 20 \mu \mathrm{g} / \mathrm{g})$ was determined in F. ulmaria sample, while the highest amount of flavonoids $(6090 \pm 253 \mu \mathrm{g} / \mathrm{g})$ was found in $R$. micrantha sample.

\subsection{Hydroxybenzoic and hydroxycinnamic derivatives}

Gallic acid (a hydroxybenzoic acid), found in C. sativa and F. ulmaria, and 5-O-caffeoylquinic acid (a hydroxycinnamic acid derivative), found in $R$. micrantha, were identified by comparison of their UV spectra and retention time with commercial standards. In the F. ulmaria sample, caffeic acid derivatives were also detected.

\subsection{Flavonols}

Flavonols were the only flavonoids found in the studied samples, being quercetin derivatives particularly abundant.
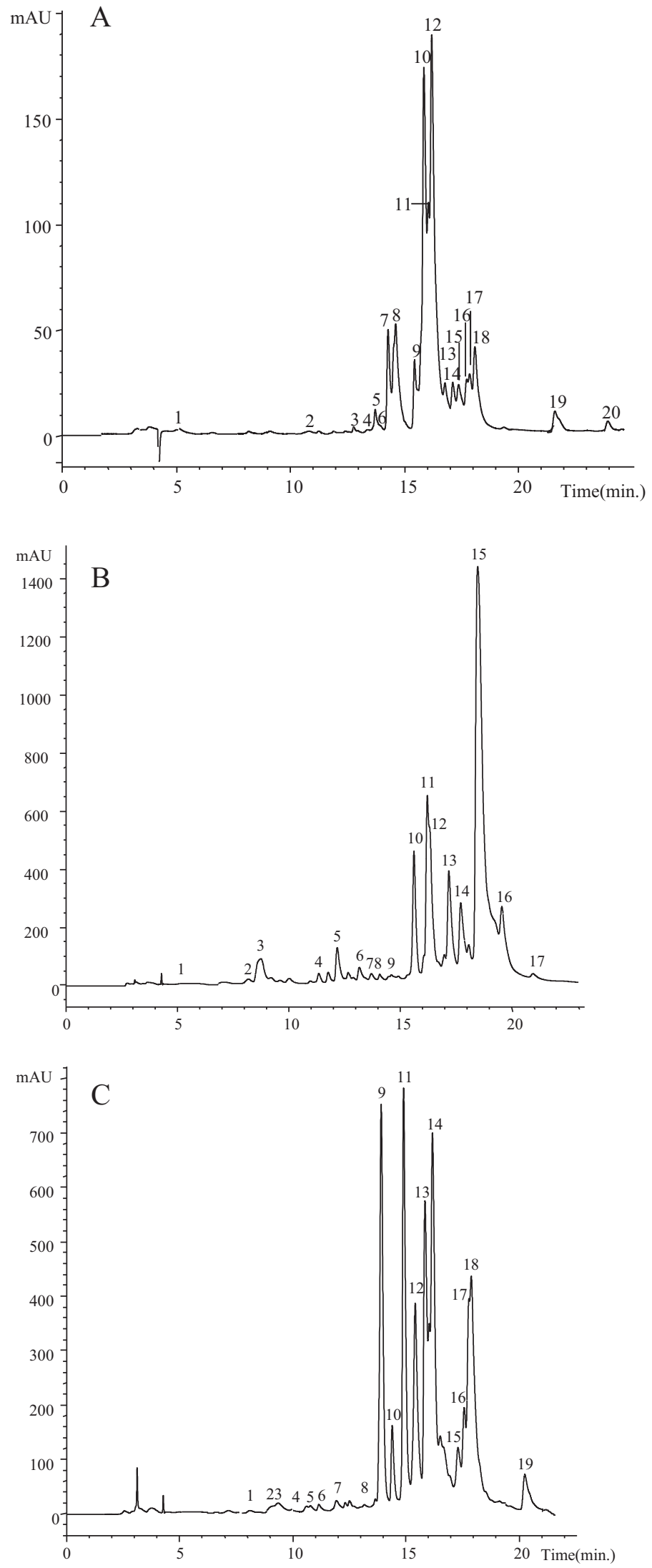

Fig. 1. Individual chromatograms of the studied wild flowers: (A) Castanea sativa; (B) Filipendula ulmaria and (C) Rosa micrantha all recorded at $370 \mathrm{~nm}$. 
Table 1

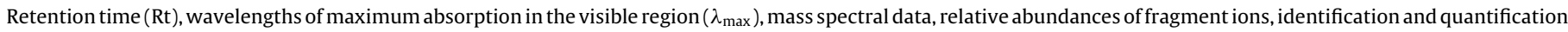
of the phenolic compounds in the studied wild flowers.

\begin{tabular}{|c|c|c|c|c|c|c|}
\hline Peak & $\mathrm{Rt}(\mathrm{min})$ & $\lambda_{\max }(\mathrm{nm})$ & $\begin{array}{l}\text { Molecular } \\
\text { ion }[\mathrm{M}-\mathrm{H}]^{-} \\
(\mathrm{m} / \mathrm{z})\end{array}$ & $\operatorname{MS}^{2}(m / z)$ & Identification & $\begin{array}{l}\text { Quantification } \\
(\mu \mathrm{g} / \mathrm{g}, \mathrm{fw})\end{array}$ \\
\hline \multicolumn{7}{|c|}{ Castanea sativa } \\
\hline 1 & 5.0 & 270 & 169 & $125(100)$ & Gallic acid & $16.71 \pm 0.62$ \\
\hline 2 & 10.3 & 280 & 289 & 245(35), 203(14), 137(21) & $(+)$-Catechin & $379.94 \pm 17.18$ \\
\hline 3 & 13.4 & 276 & 635 & $465(100), 313(15), 169(6)$ & Trigalloyl glucose & $2067.68 \pm 17.22$ \\
\hline 4 & 13.7 & 276 & 937 & 937(100), 767(4), 635(4), 465(26), 301(3) & Trigalloyl HHDP glucose & $1508.57 \pm 23.32$ \\
\hline 5 & 13.9 & 274 & 937 & $937(100), 637(8), 465(67), 301(10)$ & Trigalloyl HHDP glucose & $9854.25 \pm 73.64$ \\
\hline 6 & 14.0 & 356 & 493 & $317(100)$ & Myricetin 3-O-glucuronide & $359.41 \pm 0.09$ \\
\hline 7 & 14.1 & 358 & 479 & $317(100)$ & Myricetin 3-O-glucoside & $380.92 \pm 4.98$ \\
\hline 8 & 15.3 & 274 & 937 & 937(100), 767(2), 637(4), 467(81), 301(25) & Trigalloyl HHDP glucose & $992.26 \pm 65.69$ \\
\hline 9 & 15.6 & 354 & 609 & $301(100)$ & Quercetin 3-O-rutinoside & $65.68 \pm 7.90$ \\
\hline 10 & 15.8 & 354 & 477 & $301(100)$ & Quercetin 3-O-glucuronide & $672.55 \pm 51.58$ \\
\hline 11 & 15.9 & 276 & 937 & 937(100), 767(12), 637(12), 467(20), 301(30) & Trigalloyl HHDP glucose & $450.54 \pm 35.57$ \\
\hline 12 & 16.0 & 356 & 449 & $317(100)$ & Myricetin 3-O-pentoside & $386.14 \pm 2.94$ \\
\hline 13 & 16.1 & 356 & 463 & $301(100)$ & Quercetin 3-O-glucoside & $899.07 \pm 0.88$ \\
\hline 14 & 16.8 & 342 & 593 & $285(100)$ & Kaempferol 3-O-rutinoside & $191.58 \pm 18.99$ \\
\hline 15 & 17.1 & 356 & 623 & $315(100)$ & Isorhamnetin 3-O-rutinoside & $135.73 \pm 11.90$ \\
\hline 16 & 17.3 & 356 & 433 & $301(100)$ & Quercetin $O$-pentoside & $138.75 \pm 7.35$ \\
\hline 17 & 17.7 & 348 & 447 & $301(100)$ & Quercetin 3-O-rhamnoside & $100.75 \pm 7.50$ \\
\hline 18 & 18.0 & 356 & 477 & $315(100)$ & Isorhamnetin 3-O-glucoside & $249.33 \pm 6.70$ \\
\hline 19 & 21.6 & 354 & 609 & 463(100), 301(93) & Quercetin-O-rhamnoside-O-hexoside & $53.05 \pm 3.65$ \\
\hline 20 & 23.9 & 356 & 593 & $447(8), 285(100)$ & Kaempferol-O-rhamnoside-O-hexoside & $71.00 \pm 5.10$ \\
\hline \multicolumn{7}{|c|}{ Filipendula ulmaria } \\
\hline 1 & 4.9 & 274 & 169 & $125(100)$ & Gallic acid & $58.97 \pm 2.37$ \\
\hline 2 & 8.7 & 330 & 297 & 179(9), 161(12), 135(100) & Caffeic acid derivative & $164.04 \pm 11.96$ \\
\hline 3 & 9.0 & 276 & 785 & 785(100), 633(5), 483(7), 301(38) & Digalloyl-HHDP-glucose & $712.87 \pm 20.30$ \\
\hline 4 & 11.5 & 276 & 785 & $785(100), 633(5), 483(17), 301(56)$ & Digalloyl-HHDP-glucose & $1462.02 \pm 86.23$ \\
\hline 5 & 12.2 & 322 & 297 & $179(36), 161(27), 135(100)$ & Caffeic acid derivative & $360.40 \pm 6.19$ \\
\hline 6 & 13.9 & 276 & 785 & $785(100), 633(4), 483(6), 301(31)$ & Digalloyl-HHDP-glucose & $529.48 \pm 38.54$ \\
\hline 7 & 14.4 & 273 & 937 & 937(100), $767(4), 635(10), 465(7), 301(11)$ & Trigalloyl HHDP glucose & $464.39 \pm 69.03$ \\
\hline 8 & 14.5 & 276 & 937 & 937(100), 767(8), 635(4), 465(8), 301(21) & Trigalloyl HHDP glucose & $2091.98 \pm 108.72$ \\
\hline 9 & 15.3 & 280 & 937 & $937(100), 767(6), 635(2), 465(4), 301(12)$ & Trigalloyl HHDP glucose & $1031.90 \pm 26.27$ \\
\hline 10 & 15.6 & 354 & 609 & $301(100)$ & Quercetin-3-O- rutinoside & $484.56 \pm 75.39$ \\
\hline 11 & 16.2 & 354 & 463 & $301(100)$ & Quercetin-3-O-glucoside & $444.69 \pm 72.78$ \\
\hline 12 & 16.3 & 356 & 477 & $315(100)$ & Isorhamnetin $O$-hexoside & $542.06 \pm 11.11$ \\
\hline 13 & 17.1 & 356 & 433 & $301(100)$ & Quercetin $O$-pentoside & $444.85 \pm 24.87$ \\
\hline 14 & 17.7 & 354 & 433 & $301(100)$ & Quercetin $O$-pentoside & $376.16 \pm 28.71$ \\
\hline 15 & 18.5 & 356 & 463 & $301(100)$ & Quercetin $4^{\prime}$-O-glucoside & $2365.70 \pm 34.64$ \\
\hline 16 & 19.5 & 348 & 519 & $315(100)$ & Isorhamnetin acetylhexoside & $573.97 \pm 17.87$ \\
\hline 17 & 20.9 & 354 & 585 & 433(27), 301(100) & Quercetin pentoside derivative & $98.46 \pm 10.48$ \\
\hline \multicolumn{7}{|c|}{ Rosa micrantha } \\
\hline 1 & 8.9 & 276 & 577 & 425(36), 289(68) & Procyanidin dimer & $420.18 \pm 36.50$ \\
\hline 2 & 9.4 & 280 & 577 & $425(60), 289(65)$ & Procyanidin dimer & $475.74 \pm 39.28$ \\
\hline 3 & 9.9 & 280 & 865 & $865(100), 577(48), 287(17)$ & Procyanidin trimer & $289.80 \pm 12.03$ \\
\hline 4 & 10.2 & 280 & 289 & $245(55), 203(30), 137(14)$ & $(+)$-Catechin & $1354.14 \pm 79.43$ \\
\hline 5 & 10.7 & 326 & 353 & 191(100), 179(13), 173(2), 135(3) & 5-O-caffeoylquinic acid & $54.98 \pm 6.99$ \\
\hline 6 & 11.4 & 274 & 785 & $483(38), 301(100)$ & Digalloyl-HHDP-glucose & $397.10 \pm 62.59$ \\
\hline 7 & 12.3 & 280 & 577 & $425(72), 289(55)$ & Procyanidin dimer & $120.25 \pm 18.71$ \\
\hline 8 & 13.4 & 278 & 865 & 865(100), 577(27), 287(31) & Procyanidin trimer & $327.23 \pm 44.85$ \\
\hline 9 & 14.1 & 354 & 625 & $463(6), 301(100)$ & Quercetin-O-hexoside-O-hexoside & $439.65 \pm 15.44$ \\
\hline 10 & 14.6 & 355 & 639 & $315(100)$ & Isorhamnetin- $O$-hexoside- $O$-hexoside & $109.97 \pm 0.97$ \\
\hline 11 & 15.1 & 346 & 609 & $447(8), 285(100)$ & Kaempferol-O-hexoside-O-hexoside & $617.66 \pm 46.54$ \\
\hline 12 & 15.6 & 356 & 433 & $301(100)$ & Quercetin $O$-pentoside & $274.69 \pm 22.12$ \\
\hline 13 & 16.0 & 354 & 477 & $301(100)$ & Quercetin-3-O-glucuronide & $291.06 \pm 31.59$ \\
\hline 14 & 16.3 & 354 & 463 & $301(100)$ & Quercetin-3-O-glucoside & $442.39 \pm 18.44$ \\
\hline 15 & 17.5 & 347 & 447 & $285(100)$ & Kaempferol $\mathrm{O}$-hexoside & $152.60 \pm 24.39$ \\
\hline 16 & 17.7 & 348 & 461 & $285(100)$ & Kaempferol-3-O-glucuronide & $162.49 \pm 16.23$ \\
\hline 17 & 17.9 & 346 & 447 & $285(100)$ & Kaempferol-3-O-glucoside & $280.80 \pm 24.22$ \\
\hline 18 & 18.0 & 348 & 447 & $301(100)$ & Quercetin-3-O-rhamnoside & $270.00 \pm 17.32$ \\
\hline 19 & 20.4 & 344 & 431 & $285(100)$ & Kaempferol-3-O-rhamnoside & $60.98 \pm 10.94$ \\
\hline
\end{tabular}

Quercetin-3-O-rutinoside was found in C. sativa and F. ulmaria, quercetin-3-O-glucuronide and quercetin-3-O-rhamnoside were found in $C$. sativa and $R$. micrantha, quercetin- 4 '-O-glucoside was in found $F$. ulmaria, while quercetin-3-O-glucoside was found in all the analyzed samples. They showed similar UV spectra with $\lambda_{\max }$ at $348-356 \mathrm{~nm}$, and presented pseudomolecular ions $[\mathrm{M}-\mathrm{H}]^{-}$at $\mathrm{m} / \mathrm{z}$ $609,477,447$ and 463 , respectively, all of them releasing a unique $\mathrm{MS}^{2}$ fragment at $\mathrm{m} / \mathrm{z} 301$, corresponding to quercetin. All those compounds were positively identified according to their mass and UV characteristics and comparison with commercial standards.
Different peaks that could be associated to quercetin pentosides according to their UV and mass spectral characteristics were also found in the samples. Peaks 16 in C. sativa, 13 and 14 in F. ulmaria and 12 in $R$. micrantha showed a pseudomolecular ion $[\mathrm{M}-\mathrm{H}]^{-}$at $m / z$ 433, releasing a unique $\mathrm{MS}^{2}$ fragment at $m / z$ 301 , which allowed their identification as quercetin monopentosides. Peak 17 in F. ulmaria was also associated to an unknown a quercetin pentoside derivative owing its fragment ion at $m / z 433$. Other unknown quercetin glycosides were detected in $R$. micrantha (peak 9, $[\mathrm{M}-\mathrm{H}]^{-}$at $m / z 625$ ) and C. sativa (peak $19,[\mathrm{M}-\mathrm{H}]^{-}$at 


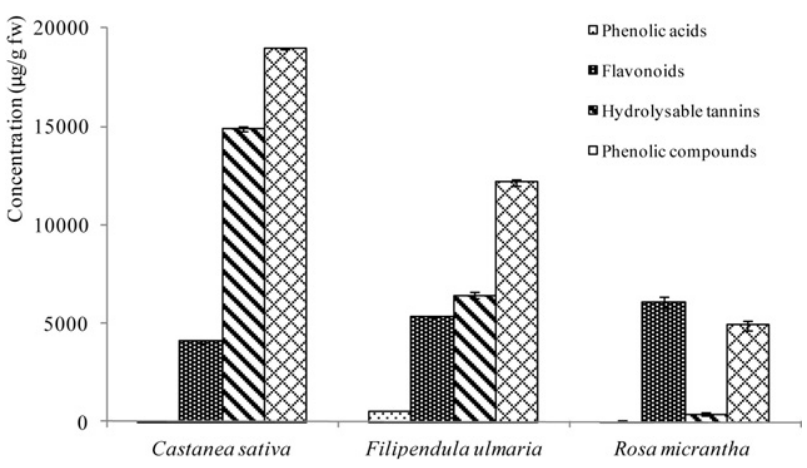

Fig. 2. Total amounts of the different classes of phenolic compounds, determined by HPLC analysis, in the studied wild flowers.

$m / z 609$ ) and identified as a quercetin $O$-hexoside- $O$-hexoside and a quercetin- $\mathrm{O}$-rhamnoside- $\mathrm{O}$-hexoside, respectively, according to their pseudomolecular ions and fragmentation patterns.

Isorhamnetin derivatives were also found in all the studied samples, presenting UV spectra with $\lambda_{\max }$ at $348-356 \mathrm{~nm}$, and different pseudomolecular ions that release a unique $\mathrm{MS}^{2}$ fragment at $m / z 315$, coherent with isorhamnetin. Peaks 15 and 18 in $C$. sativa were positively identified as isorhamnetin-3-O-rutinoside and isorhamnetin-3-O-glucoside by comparison with commercial standards, whilst the identity of the other peaks was established according to their pseudomolecular ions and fragmentation patterns and identified as isorhamnetin-O-hexoside (peak 12 in $\mathrm{F}$. ulmaria, $[\mathrm{M}-\mathrm{H}]^{-}$at $m / z 477$ ), isorhamnetin acetylhexoside (peak 16 in F. ulmaria, $[\mathrm{M}-\mathrm{H}]^{-}$at $\mathrm{m} / z$ 519), isorhamnetin-O-hexoside-Ohexoside (peak 10 in $R$. micrantha, $[\mathrm{M}-\mathrm{H}]^{-}$at $m / z$ 639).

Kaempferol derivatives were found in $C$. sativa and $R$. micrantha. Peak 14 in C. sativa (kaempferol-3-O-rutinoside) and peaks 16 (kaempferol-3-O-glucuronide), 17 (kaempferol-3-O-glucoside) and 19 (kaempferol-3-O-rhamnoside) in $R$. micrantha were positively identified according to their UV and mass spectra and comparison with standards. Peak 20 in C. sativa (kaempferol$O$-rhamnoside- $O$-hexoside, $[\mathrm{M}-\mathrm{H}]^{-}$at $\mathrm{m} / z$ 593) and peak 15 in $R$. micrantha (kaempferol-O-hexoside, $[\mathrm{M}-\mathrm{H}]^{-}$at $\mathrm{m} / \mathrm{z} 447$ ) were assigned according to their pseudomolecular ions and fragmentation patterns.

C. sativa was the only sample that presented myricetin derivatives, which could be identified as myricetin-3-O-glucuronide (peak 6), myricetin-3-O-glucoside (peak 7) and myricetin 3-Opentoside (peak 12) by comparison of their UV and mass spectra with authentic standards.

\subsection{Procyanidins}

Peaks 2 and 4 in $C$. sativa and $R$. micrantha samples were identified as (+)-catechin by comparison of UV spectrum and retention time with a commercial standard. Procyanidin oligomers were also detected in $R$. micrantha sample. Peaks 1, 2, 3, 7 and 8 showed UV spectra with $\lambda_{\max } 276-280 \mathrm{~nm}$, characteristic of proanthocyanidins. Peaks 1,2 and 7 presented a pseudomolecular ions corresponding to procyanidin dimers $\left([\mathrm{M}-\mathrm{H}]^{-}\right.$at $\left.m / z 577\right)$, and peaks 3 and 8 to procyanidin trimers ([M-H $]^{-}$at $\left.m / z 865\right)$.

\subsection{Hydrolyzable tannins}

All the studied plant extracts presented compounds that showed UV spectral coherent with galloyl and hexahydroxydiphenol (HHDP) derivatives (Cantos et al., 2003), and in accordance with their mass spectra data, they were associated to different isomers of trigalloyl glucopyranose and di, trigalloyl-hexahydroxydiphenoyl glucopyranose (Table 1). According to the literature, the main characteristic in the mass spectra of these compounds was the deprotonated molecula $[\mathrm{M}-\mathrm{H}]^{-}(m / z 483,635,787,939,785,937)$ and the loss of one or more galloyl groups $(152 \mu \mathrm{m})$ and/or gallic acid $(170 \mu \mathrm{m})$ (Salminen et al., 1999; Zywicki et al., 2002). Thus, peak 3 in C. sativa with a pseudomolecular ion $[\mathrm{M}-\mathrm{H}]^{-}$at $m / z 635$ and MS $^{2}$ fragment ions at $m / z 465$ (loss of gallic acid residue), $m / z$ 313 (loss of a galloyl residue) and $m / z 169$ (gallic acid) was identified as trigalloyl glucose.

Peaks 4, 5, 8 and 11 in C. sativa and 7, 8 and 9 in F. ulmaria presented a pseudomolecular ion $[\mathrm{M}-\mathrm{H}]^{-}$at $m / z 937$ and they were identified as different isomers of trigalloyl-HHDP-glucopyranose. The $[\mathrm{M}-\mathrm{H}]^{-}$ion suffered the loss of gallic acid $(\mathrm{m} / \mathrm{z} 797)$ and the fragments $m / z 635,465$ were due to the loss of hexahydroxydiphenoyl moieties from the $[\mathrm{M}-\mathrm{H}]^{-}$and $[\mathrm{M}-\mathrm{H}-\text { gallic acid }]^{-}$ions respectively. Similar ellagitannins have already been reported in $C$. sativa heartwood (Sanz et al., 2010).

Peaks 3, 4 and 6 in F. ulmaria and 6 in R. micrantha with an $m / z$ 785 were identified as isomers of digalloyl-HHDP-glucopyranose. Their fragmentation pattern involved the loss of galloyl and hexahydroxydiphenoyl moieties ( $m / z 633$ and 483, respectively). The fragment at $m / z 301$ besides the $[\mathrm{M}-\mathrm{H}-302]^{-}$ion represented an evidence of the presence of an HHDP group [ellagic- $\mathrm{H}]^{-}$in the molecule.

As far as we know, there was no information on the phenolic composition of $C$. sativa and $R$. micrantha flowers, but a few previous studies have been published dealing with the phenolic composition of F. ulmaria flowers from Russia (Krasnov et al., 2006, 2009; Shilova et al., 2006), Poland (Fecka, 2009) and Austria (Pemp et al., 2007). Some differences were found in the F. ulmaria sample (flowers from Portugal) studied herein, including the presence of different compounds such as isorhamnetin glucoside derivatives and caffeic acid derivatives. Krasnov et al. (2006, 2009) identified and isolated two quercetin glucosides (filimarin and isoquercitrin) from F. ulmaria aerial parts during flowering, and Fecka (2009) reported different ellagitannins such as rugosin A, B, D and E, which were not found in the sample herein studied. Pemp et al. (2007) only described flavonols in F. ulmaria sample and they did not identify any ellagitannin. Samples from Poland $(132 \pm 18 \mathrm{mg} / \mathrm{g}$ dw; Fecka, 2009) presented a higher concentration of phenolic compounds than the sample studied here $(60 \pm 0.8 \mathrm{mg} / \mathrm{g} \mathrm{dw}$; data converted in dry weight basis excluding the moisture content). It was not possible to compare to the quantity found in the sample from Austria, because the results were expressed in percentage (Pemp et al., 2007), neither with those of Shilova et al. (2006) that used thin-layer chromatography for the analysis of phenolic compounds.

\subsection{Antifungal activity of the extracts from wild flowers}

In the last years, the number of Candida species resistant to the common antifungal agents has been increasing (Bonjar, 2004). In order to overcome this problem it is of major importance to identify new compounds, especially natural ones, that are active against the most broaden spectrum of these species. In this study, the principal aim was to determine, for the first time, the antifungal effect of $C$. sativa, F. ulmaria and $R$. micrantha flowers extracts against four Candida species.

The minimum inhibitory concentration (MIC) values (Table 2) ranged from concentrations under 0.05 to $0.625 \mathrm{mg} / \mathrm{mL}$. Furthermore, it is important to highlight that the extracts presented different activity against the different Candida species under study. According to the classification established by Aligiannis et al. (2001) and with the values present in Table 2 it is possible to assume that the extract of $F$. ulmaria presented a moderate activity against C. albicans, but a strong effect against the other three species. $C$. sativa extract presented similar behavior, with the exception of 
Table 2

Minimum inhibitory concentrations (MIC; mg/mL) of the wild flowers extracts against Candida species.

\begin{tabular}{|c|c|c|c|c|}
\hline & C. albicans & C. glabrata & C. parapsilosis & C. tropicalis \\
\hline Castanea sativa & 0.625 & $<0.05$ & $<0.05$ & 0.625 \\
\hline Filipendula ulmaria & 0.625 & $<0.05$ & $<0.05$ & 0.155 \\
\hline Rosa micrantha & 0.05 & $<0.05$ & $<0.05$ & 0.155 \\
\hline
\end{tabular}
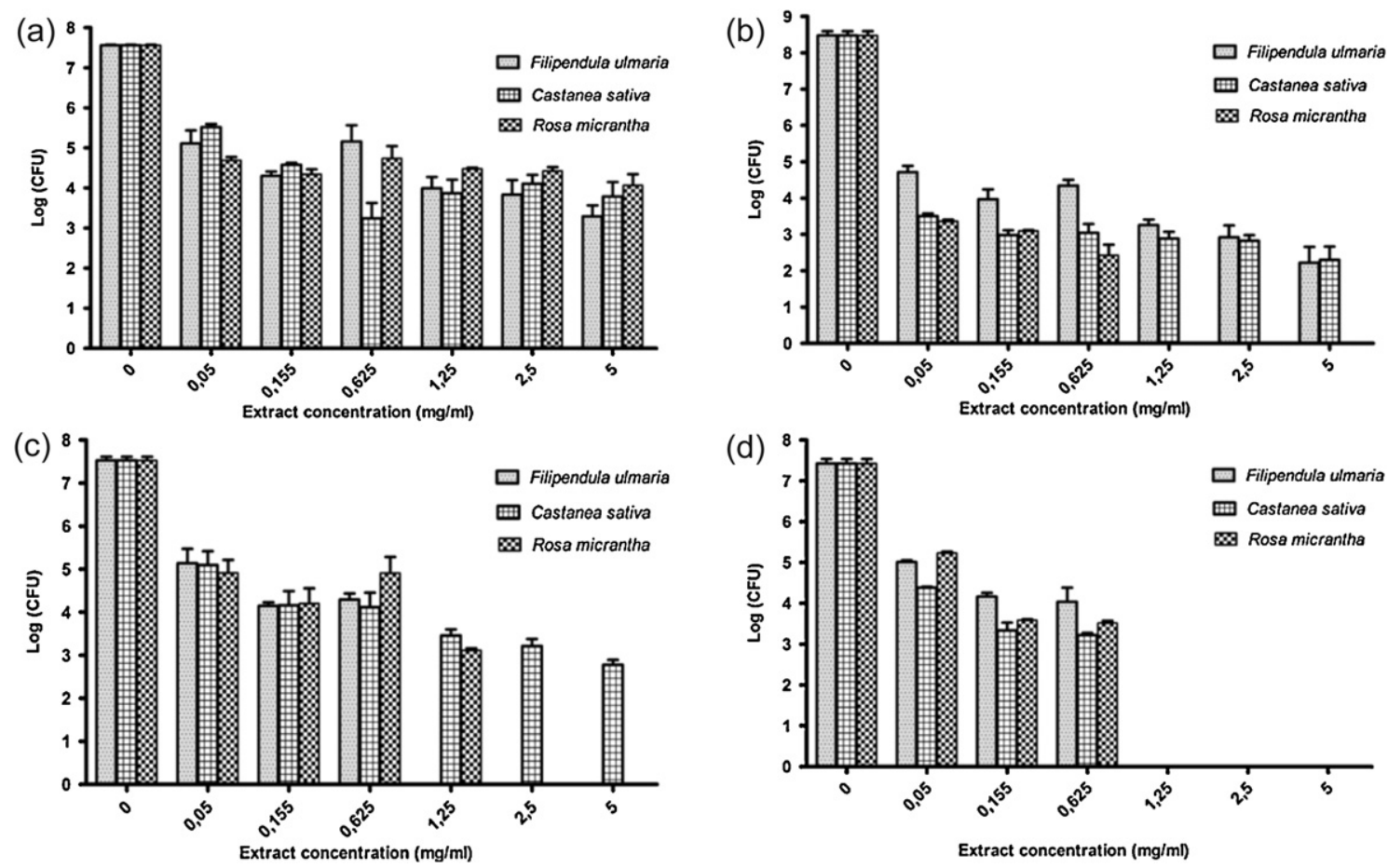

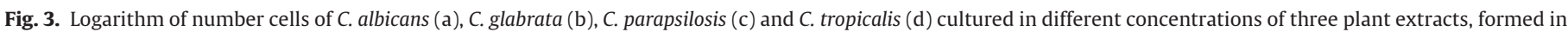
SDB after $48 \mathrm{~h}$. Error bars represent standard deviation.

C. tropicalis, against which it also presented a moderate activity. Regarding $R$. micrantha extract, a different profile was found, since it showed a strong effect against the four strains assayed. This higher activity of $R$. micrantha extract could explain the traditional use of this plant to treat acne and skin conditions closely related with Candida species (Jain et al., 2010). Additionally, the effect of the extracts on the viability of the Candida species was assessed by CFU counts (Fig. 3). This evaluation is of utmost importance to distinguish between the fungicidal and fungistatic effects.

The results showed that all the samples presented a strong activity against the four Candida species studied. It should be noticed that all the extracts caused at least $2 \log$ of reduction for all strains, at the lowest concentration tested $(0.05 \mathrm{mg} / \mathrm{mL})$. C. glabrata (Fig. 3) presented the highest initial inhibition for all the extracts tested, with more than $3 \log$ of reduction. However, only $R$. micrantha extract was able to completely eliminate all $C$. glabrata cells, in concentrations $1.25 \mathrm{mg} / \mathrm{mL}$. These results confirm the fungicidal effect of this plant against C. glabrata, in detriment of the fungistatic effect of the other two extracts. C. sativa, F. ulmaria and R. micrantha extracts were able to cause a similar effect in $C$. parapsilosis and $C$. tropicalis at low concentrations. However, $C$. sativa sample was not able to cause a total inhibition of the former species, even in the highest concentrations tested, and $R$. micrantha sample was only able to cause a significant CFUs reduction at concentrations above than $2.5 \mathrm{mg} / \mathrm{mL}$.

C. tropicalis demonstrated a strong susceptibility to all the samples, and more important at concentrations above $1.25 \mathrm{mg} / \mathrm{mL}$, all the assayed extracts were able to cause total inhibition of the growth of this fungi species (Fig. 3).
Although being $C$. tropicalis often associated with urinary tract infections (Silva et al., 2011) and F. ulmaria traditionally used on these infections, it was not observed any distinct effect of its extract. Interestingly, despite being $C$. tropicalis the NCAC species with the highest genetic similarity to C. albicans (Butler et al., 2009), no similarities were observed in terms of their sensitivity to the assayed extracts. On the contrary, C. albicans was the species with the lowest rate of inhibition and none of the flowers extracts tested was able to cause a total inhibition effect.

Overall, extracts of C. sativa, F. ulmaria and R. micrantha revealed promising antifungal effects against Candida species. Hydrolysable tannins (e.g. tri and digalloyl HHDP glucose) were the main group of phenolic compounds in $C$. sativa and $F$. ulmaria samples, while flavonoids (e.g. (+)-catechin and procyanidin dimers and trimers) were the most abundant group in $R$. micrantha. Thus, the stronger effect showed by this latter against all the Candida species and, particularly its fungicide effects in $C$. glabrata, might be related to the mentioned flavonoids that were inexistence in the other samples. Furthermore, the present manuscript highlights the importance of natural products in discovery of new antifungal compounds.

\section{Acknowledgements}

L. Barros, C. Alves and S. Silva thank to FCT, POPH-QREN and FSE for their grants (SFRH/BPD/4609/2008, SFRH/BD/72742/2010 and $\mathrm{BPD} / 71076 / 2010$, respectively). M. Dueñas thanks to the Programa Ramón y Cajal for a contract. The GIP-USAL is financially supported by the Spanish Ministerio de Ciencia e Innovación through the Consolider-Ingenio 2010 Programme (FUN-C-FOOD, 
CSD2007-00063), and Junta de Castilla y León (Grupo de Investigación de Excelencia, GR133).

\section{References}

Aligiannis, N., Kalpotzakis, E., Mitaku, S., Chinou, I.B., 2001. Composition and antimicrobial activity of the essential oils of two Origanum species. J. Agric. Food Chem. 40, 4168-4170.

Barros, L., Cabrita, L., Vilas-Boas, M., Carvalho, A.M., Ferreira, I.C.F.R., 2011a. Chemical biochemical and electrochemical assays to evaluate phytochemicals and antioxidant activity of wild plants. Food Chem. 127, 1600-1608.

Barros, L., Dueñas, M., Ferreira, I.C.F.R., Carvalho, A.M., Santos-Buelga, C., 2011b. Use of HPLC-DAD-ESI/MS to profile phenolic compounds in edible wild greens from Portugal. Food Chem. 127, 169-173.

Barros, L., Oliveira, S., Carvalho, A.M., Ferreira, I.C.F.R., 2010. In vitro antioxidant properties and characterization in nutrients and phytochemicals of six medicinal plants from the Portuguese folk medicine. Ind. Crops Prod. 32, 572-579.

Bonjar, S., 2004. Evaluation of antibacterial properties of some medicinal plants used in Iran. J. Ethnopharmacol. 94, 301-305.

Butler, G., Rasmussen, M.D., Lin, M.F., Santos, M.A.S., Sakthikumar, S., et al., 2009. Evolution of pathogenicity and sexual reproduction in eight Candida genomes. Nature 459, 657-662.

Calliste, C.-A., Trouillas, P., Allais, D.-P., Simon, A., Duroux, J.-L., 2001. Free radical scavenging activities measured by electron spin resonance spectroscopy and B16 cell antiproliferative behaviors of seven plants. J. Agric. Food Chem. 49, 3321-3327.

Camejo-Rodrigues, J., Ascensão, L., Bonet, M.À., Vallès, J., 2003. An ethnobotanical study of medicinal and aromatic plants in the Natural Park of "Serra de São Mamede" (Portugal). J. Ethnopharmacol. 89, 199-209.

Cantos, E., Espin, J.C., Lopez-Bote, C., De la Hoz, L., Ordonez, J.A., Tomás-Barberán, F.A., 2003. Phenolic compounds and fatty acids from acorns (Quercus spp.) the main dietary constituent of free-ranged Iberian pigs. J. Agric. Food Chem. 51, 6248-6255.

Carvalho, A.M., 2010. Plantas y Sabiduría Popular del Parque Natural de Montesinho Un Estudio Etnobotánico en Portugal. CSIC, Biblioteca de Ciencias 35, Madrid.

Dorman, H.J.D., Deans, S.G., 2000. Antimicrobial agents from plants: antibacterial of plant volatile oils. J. Appl. Microbiol. 88, 308-316.

Erasto, P., Bojase-Moleta, G., Majinda, R.R., 2004. Antimicrobial and antioxidant flavonoids from the root wood of Bolusanthus speciosus. Phytochemistry 65, 875-880.

Fecka, I., 2009. Qualitative and quantitative determination of hydrolysable tannins and other polyphenols in herbal products from meadowsweet and dog rose. Phytochem. Anal. 20, 177-190.

Guimarães, R., Barros, L., Carvalho, A.M., Ferreira, I.C.F.R., 2010. Studies on chemical constituents and bioactivity of Rosa micrantha: an alternative antioxidants source for food, pharmaceutical, or cosmetic applications. J. Agric. Food Chem. 58, 6277-6284.

Hajjeh, R.A., Sofair, A.N., Harrison, L.H., Lyon, G.M., Arthington-Skaggs, B.A., Mirza, S.A., Phelan, M., Morgan, J., Lee-Yang, W., Ciblak, M.A., Benjamin, L.E., Sanza, L.T., Huie, S., Yeo, S.F., Brandt, M.E., Warnock, D.W., 2004. Incidence of bloodstream infections due to Candida species and in vitro susceptibilities of isolates collected from 1998 to 2000 in a population-based active surveillance program. J. Clin. Microbiol. 42, 1519-1527.

Harbourne, N., Marete, E., Jacquier, J.C., O'Riordan, D., 2009. Effect of drying methods on the phenolic constituents of meadowsweet (Filipendula ulmaria) and willow (Salix alba). LWT 42, 1468-1473.
Jain, A., Jain, S., Rawat, S., 2010. Emerging fungal infections among children: a review on its clinical manifestations, diagnosis, and prevention. J. Pharm. Bioallied Sci. 2, 314-320.

Krasnov, E.A., Raldugin, V.A., Avdeeva, E.Y., 2009. Filimarin a new flavanol glycoside from Filipendula ulmaria and its antioxidant activity. Pharm. Chem. J. 43 613-614.

Krasnov, E.A., Raldugin, V.A., Shilova, I.V., Avdeeva, E.Y., 2006. Phenolic compounds from Filipendula ulmaria. Chem. Nat. Prod. 42, 148-151.

National Committee For Clinical Laboratory Standards (NCCLS), 2002. Reference Method for Broth Dilution Antifungal Susceptibility Testing of Yeast. Approved Standard. NCCLS Document M27-A2. National Committee for Clinical Laboratory Standards, Wayne, PA.

Neves, J.M., Matosa, C., Moutinho, C., Queiroz, G., Gomes, L.R., 2009. Ethnopharmacological notes about ancient uses of medicinal plants in Trás-os-Montes (northern of Portugal). J. Ethnopharmacol. 124, 270-283.

Novais, M.H., Santos, I., Mendes, S., Pinto-Gomes, C., 2004. Studies on pharmaceutical ethnobotany in Arrabida Natural Park (Portugal). J. Ethnopharmacol. 93 183-195.

Pemp, E., Reznicek, G., Krenn, L., 2007. Fast quantification of flavonoids in Filipendulae ulmariae flos by HPLC/ESI-MS using a nonporous stationary phase. J. Anal. Chem. 62, 669-673.

Pfaller, M.A., Diekema, D.J., 2007. Epidemiology of invasive candidiasis: a persistent public health problem. Clin. Microbiol. Rev. 20, 133-163.

Rauha, J.-P., Remes, S., Heinonen, M., Hopia, A., Kahkonen, M., Kujalac, Y., Pihlajac, K., Vuorela, H., Vuorela, P., 2000. Antimicrobial effects of Finnish plant extracts containing flavonoids and other phenolic compounds. Int. J. Food Microbiol. 56, $3-12$.

Redding, S., Kirkpatrick, W., Coco, B., Sadkowski, L., Fothergill, A., Rinaldi, M., Eng T., Patterson, T., 2002. Candida glabrata oropharyngeal candidiasis in patients receiving radiation treatment for head and neck cancer. J. Clin. Microbiol. 40 $1879-1881$.

Ruhnke, M., 2006. Epidemiology of Candida albicans infections and role of nonCandida-albicans yeasts. Curr. Drug Target. 7, 495-504.

Salminen, J.P., Ossipov, V., Loponen, J., Haukioja, E., Pihlaja, K., 1999. Characterisation of hydrolysable tannins from leaves of Betula pubescens by high performance liquid chromatography mass spectrometry. J. Chromatogr. A 864, 283-294.

Sanz, M., Cadahia, E., Esteruelas, E., Muñoz, A.M., Simon, B.F., Hernandez, T., Estrella I., 2010. Phenolic compounds in chestnut (Castanea sativa Mill) heartwood. Effect of toasting at cooperage. J. Agric. Food Chem. 58, 9631-9640.

Shilova, I.V., Krasnov, E.A., Korotkova, E.I., Nagaev, M.G., Lukina, A.N., 2006. Antioxidant properties of extracts from the above-ground parts of Filipendula ulmaria. Pharm. Chem. J. 40, 660-662.

Silva, S., Henriques, M., Martins, A., Oliveira, R., Williams, D., Azeredo, J., 2010. Silicone colonization by non-Candida albicans Candida species in the presence of urine. J. Med. Microbiol. 59, 747-754.

Silva, S., Negri, M., Henriques, M., Oliveira, R., Williams, D., Azeredo, J., 2011. Candida glabrata, Candida parapsilosis and Candida tropicalis: biology epidemiology pathogenicity and antifungal resistance. FEMS Microbiol. Rev. 36, 288-305.

Soll, D.R., 2002. Candida commensalism and virulence: the evolution of phenotypic plasticity. Acta Trop. 81, 101-110.

Tepe, B., Daferera, D., Sokmen, M., Polissiou, M., Sokmen, A., 2004. In vitro antimicrobial and antioxidant activities of the essential oils and various extracts of Thymus eigii. J. Agric. Food Chem. 52, 1132-1137.

Zywicki, B., Reemtsma, T., Jekel, M., 2002. Analysis of commercial vegetable tanning agents by reverse-phase liquid chromatography-electrospray ionizationtandem mass spectrometry and its application to wastewater. J. Chromatogr. A 970, 191-200. 